\title{
UED Curriculum System Construction Based on Dynamic Studio System*
}

\author{
Gaosheng Luo \\ Xinyu University \\ Xinyu, China 338004
}

\begin{abstract}
The User Experience Design (UED) widely includes design psychology, human engineering, interaction design, information architecture, content text, visual design, voice design, interaction between human and machine, situation understanding, users' observation and so on. It is an integrated multidiscipline, whose features decided that it cannot be fixed and static rather than instantly absorbing external new concept and method. Thus, the construction of UED course system should be dynamic rather than static a course system.
\end{abstract}

Keywords-studio system; dynamization; user experience design; curriculum system

\section{INTRODUCTION}

User Experience Design (UED) is a comprehensive interdisciplinary discipline that integrates multidisciplinary knowledge. It emphasizes the comprehensiveness, intersectionality, and real-time nature of the curriculum and strengthens the connection among psychology, computer science and literature. Not only does it require support from the professional curriculum knowledge such as cognitive science, emotions and design, usability evaluation methods, structural design and product design, but also the support of cross-disciplinary knowledge such as sensor theory, C language program design, and mechanical principles. The Hong Kong Polytechnic University's postgraduate courses are divided into professional foundation and professional skills. They jointly conduct in the form of theoretical discussions and project practice. Its advantages are that short-term curriculum teaching and studio teaching are conducted at the same time, of which short-term curriculum structure is clear and teaching is concentrated; studio teaching forms are varied, from personal creativity to team work. The curriculum system is divided into public core courses, professional core courses, seminar topics, and elective courses. The details are as following "Fig. 1":

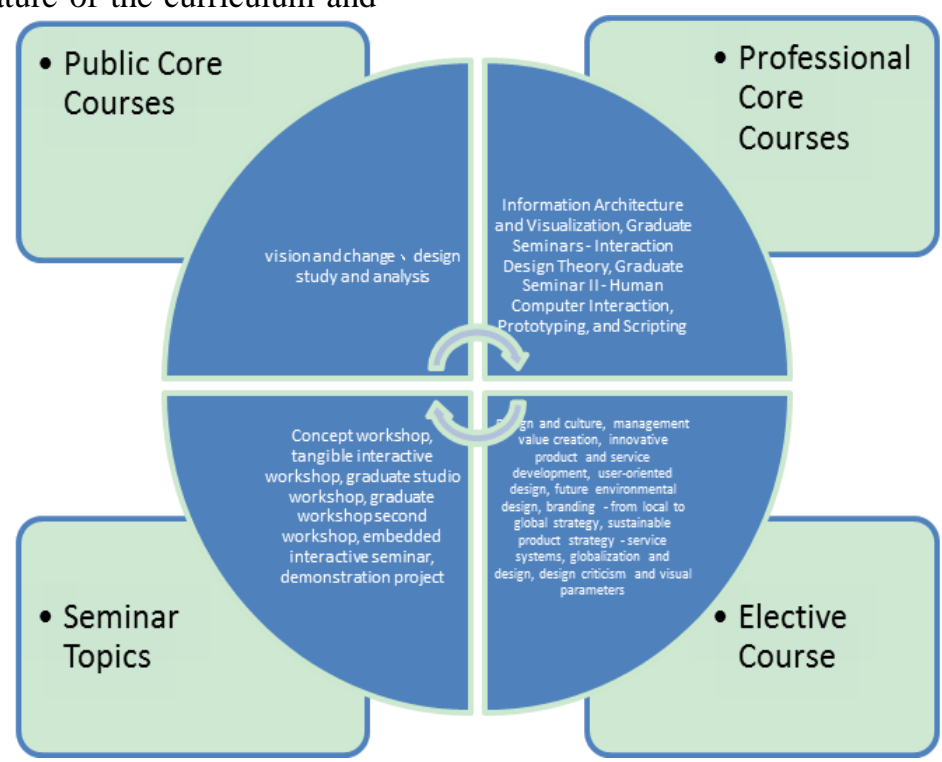

Fig. 1. The details of the curriculum system.

\section{DYNAMIZATION OF UED COURSE SYSTEM BASED ON STUDIO SYSTEM}

As for UED system, the arrangement of curriculums are

*The dissertation is part of Educational Science planning Fund Project of the Ministry of Education of Jiangxi Province (NO: 16YB167). gradually become difficult from simple level, meanwhile they pay attention to knowledge logic structures and development progress equally, focus on vertical and horizontal development and equally treat knowledge teaching as important as innovative practice. The dynamic cycled system based on theory-practice - theory-re-practice 
pattern aims to construct perfect UED knowledge framework for students.

\section{A. The Dynamization of the Horizontal Cross Integration System for UED Course}

The core of the horizontal organization of curriculum is integration. Integration breaks the boundaries of traditional textbook content and disciplines, and it focuses on breadth of knowledge rather than depth and emphasizes the application of knowledge. Within the UED curriculum system, it is necessary to pay attention to the horizontal development of the curriculum system, and to strengthen the integration of multiple disciplines through integration. For example, in the course of information structure, the basic curriculum design is used for reference first, and cross-cutting and marginal knowledge are taken as the starting point; secondly, from the perspective of visual perception development using intelligent structures, to refer to cognitive psychology methodology and take advantage of modern and post-modern art. Then, starting from the development path of visual perception, it is available to borrow cognitive psychology, and introduce he concepts of modern art and postmodern art.

\section{1) Integration with other design curriculums:}

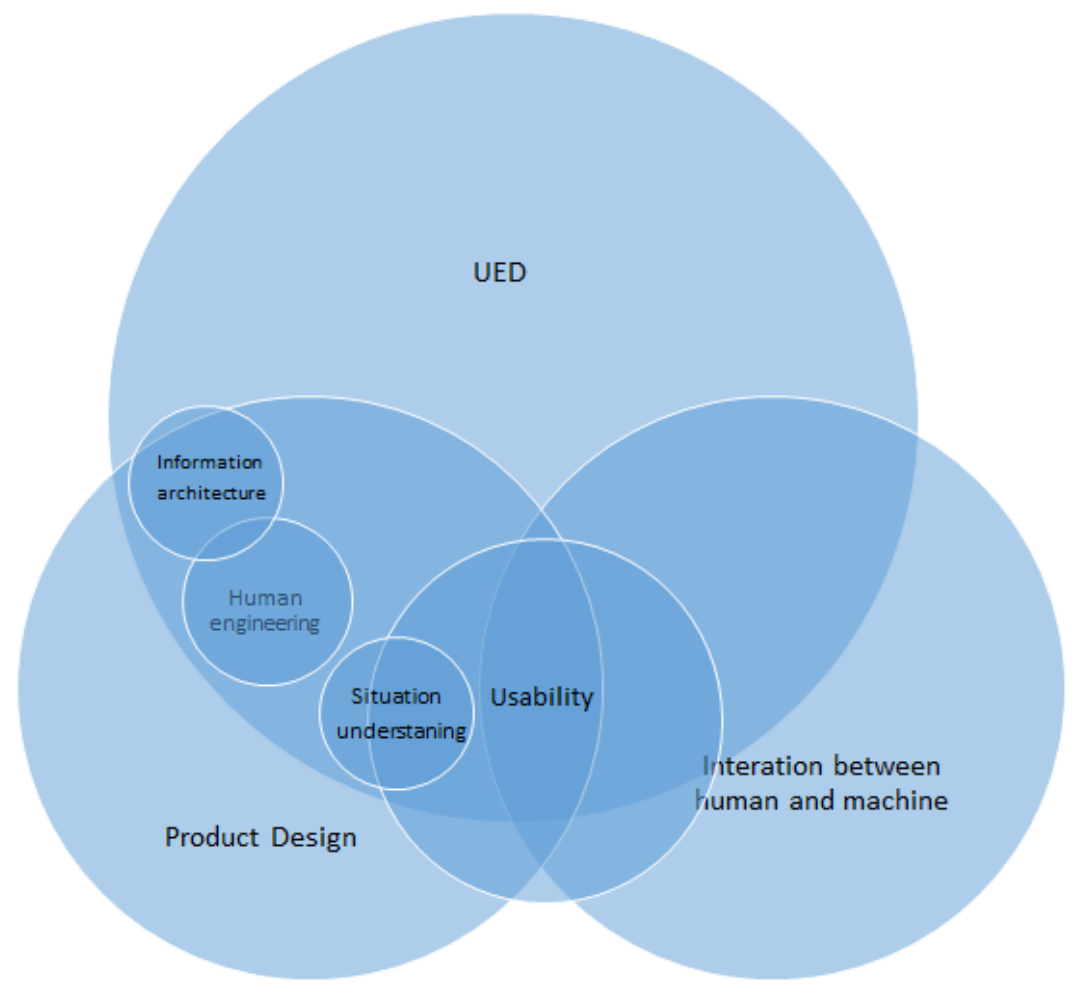

Fig. 2. Relationship with other design courses.

UED is a multi-disciplinary product integrating visual communication design, industrial design, cognitive psychology and human factors engineering, user experience, human-machine interface design or human-computer interaction design. The author draws a curriculum diagram with other design curriculums in "Fig. 2", from which we can clearly see the intersection relationship between UED and other design curriculums. The graduate program of the Illinois Institute of Technology's School of the Arts is divided into eight parts. They are Communication Design, Interaction, Product Design, Design Planning, Systems, and Research, Core Courses, Foundation courses. The usercentered design concept runs through the course content settings throughout the course settings. For example, the interface design is a visual medium for human-computer interaction. It usually includes hardware interface design and software interface design. It belongs to visual design, cognitive design, ergonomics, computer science and psychology and other comprehensive disciplines.
2) Integration with other disciplines' curriculums: First, the cross-convergence with technical engineering disciplines. Logical thinking is an essential ability for an excellent interaction designer. The discipline of technical engineering fosters the students' overall view and careful logical thinking. This way of thinking is the most difficult for art students to master and simultaneously design interactive skills. In addition, many courses in the technical engineering discipline can improve students' technical understanding ability so as to students are more comfortable with the complex information architecture and interaction process. Second, the Integration with psychology courses. User experience is a subjective and abstract concept. Individual differences lead to different behaviors and results. These differences in psychology, emotion, behavior, and thinking all belong to the category of psychology. In this area, we need to learn how to accurately locate important variables that affect the user experience of the product, such as 
graphics, materials, sounds, colors, or other abstract elements. These important variables are the key factors to improve the quality of user experience. Third is the integration of disciplines of literature and music. The user experience is a kind of subjective thinking, which focuses on the emotional changes in the use of products, as well as the interaction between people and products, and the surrounding environment. Creative classes such as music, movies, and literature can inspire students' subtle emotions. Many designers in Silicon Valley have education background in creative disciplines. Many designers in UED industry will also choose courses such as literature and music during their college days. The thinking methods and dimensions of these creative professions are connected with experience design as in "Fig. 3".

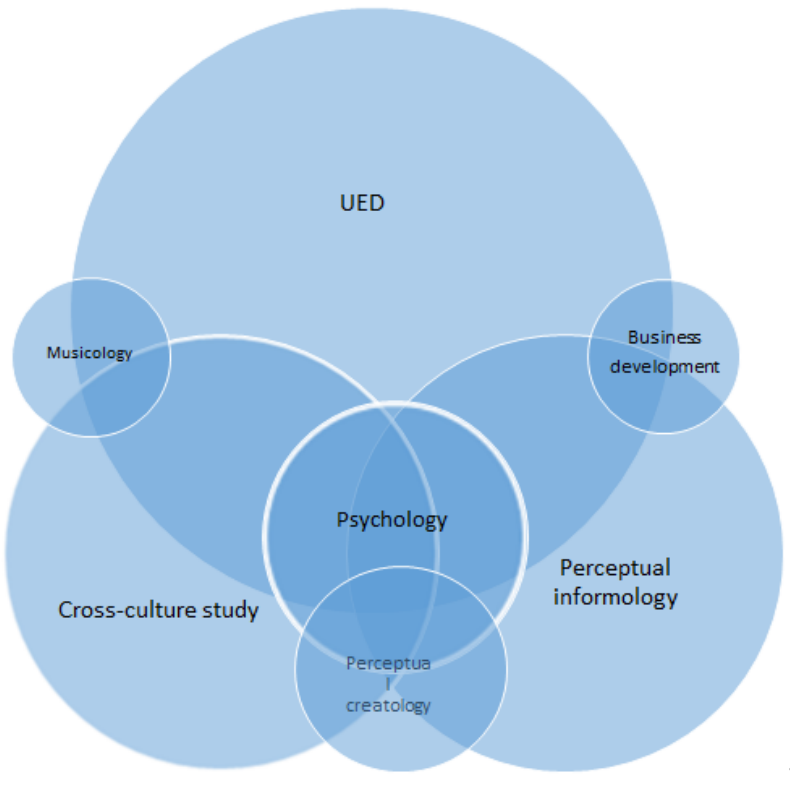

Fig. 3. Relationship with other disciplines' curriculums.

\section{B. The Dynamization of the Vertical Cross-convergence System for UED Courses}

The UED curriculum system emphasizes the principle of vertical organization. Its core concept is sequence. When arranging learning activities, it is necessary to follow a sequence from simple level to complex, that is, after learning concisely and involving fewer elements, to conduct comprehensive learning of multiple factors. In the design of the UED curriculum system, students can start from the theory and learn from UED related theoretical courses, or begin with basic courses such as graphics and symbols. Tsinghua University has followed the rules from simple to difficult, from single to complex, from the undergraduate information arts department to the interactive media arts institute. For example, in the sophomores' education, basic elective courses such as digital graphics and interactive multimedia are added to several UED modules. The purpose of the digital graphics course is to allow students to use computer tools to complete creative designs such as graphic icons and texts, and to lay a foundation for courses such as interaction design for junior students. In interactive multimedia courses, students are required to master a variety of animation design software and skillfully collaborate with other graphic design software to design and enhance students' interactive prototyping capabilities. In the third and fourth year, elective modules establish design core courses such as interface design methods and soft product development and so on.

Take the interaction design direction of the Central Saint Martins as an example, the curriculum arrangements in the first two years are based on the principles of development and progress. The first year's courses include painting, printing, publishing, photography, illustration design, advertising, animation, computer and multimedia software design. The design basis learned in the first year helps students to learn in depth in the second year. The second year begins with a comprehensive arrangement of courses and course content based on the student's voluntary choice of professional direction. The school will establish more practical courses in the curriculum system; during the second year of study, it emphasizes detailed learning methods, tasks, methods of production, and open systems, and other core technologies; the third year students need to study independently and manage their own Time with high enthusiasm. This year, students can choose to participate in social practice so as to prepare themselves for a job or continue their studies, and complete their graduation works.

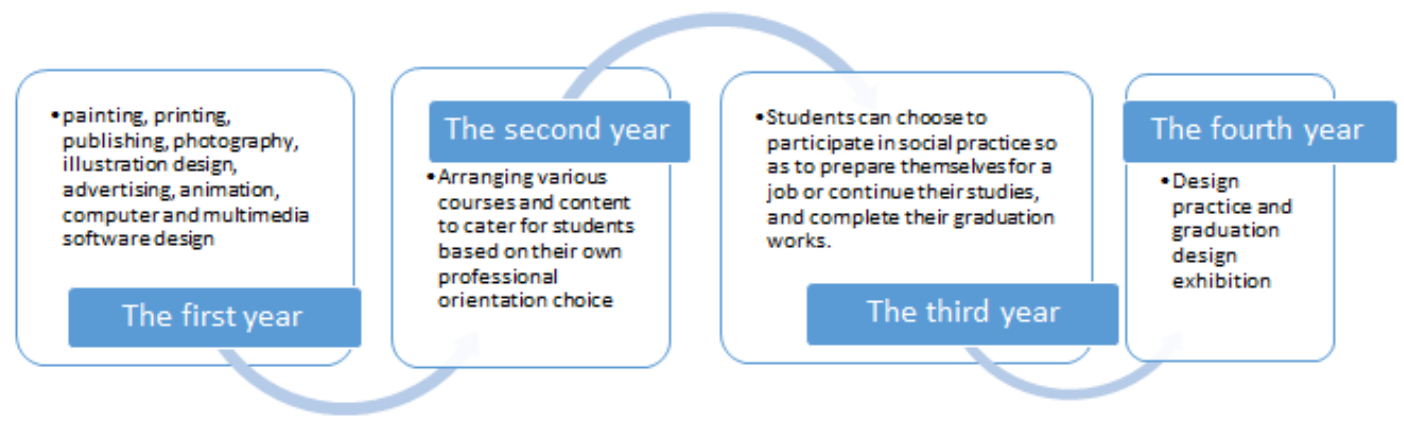

Fig. 4. Curriculum system. 


\section{DYNAMIZATION OF CONSTRUCTION APPROACH FOR UED COURSE SYSTEM BASED ON STUDIO STYTEM}

Although it is impossible to design user experience, the course system, such as environment, interface, story related to user experience can be designed. The frontier ability and intersectionality lead to the dynamic feature of UED teaching, which are flexible application, creative study and application and adjustment at any time.

\section{A. UED Training Program Design}

The job titles related to UED are summarized to determine the focus of personnel training for animation designers, visual designers, front-end development engineers, interaction designers, and user researchers in the undergraduate interactive design curriculum system. First, UED's overall training program design needs to take the project course as an entry point to design the curriculum category, and realize the transition from the discipline design to the center of the process design or work task. Second, from the macro perspective, it is necessary to incorporate the relevant protection conditions for the development of professional competence into the UED training program. For example, dual-qualified teachers, teaching situation design, and conditions for construction of training equipment and so on to ensure the formation of students' professional competence. Third, teaching evaluation must be included in the design of UED training programs. For example, feedback on the teaching effect, teaching management, teaching environment, employment situation of graduates and employment market conditions, etc., in order to facilitate the correct evaluation of teaching quality.

\section{B. The Establishment of UED Curriculum System Platform}

During the establishment of curriculum system platform, the core of the teaching based on the enterprise project projects provided by off-campus practice bases or industrial cooperation companies must always run through the entire curriculum system. The curriculum system platform constructed in this way will always carry out teaching activities centered on industrial issues, and will constantly continue to use the industrial application as the UED talent training target and seek solutions for related issues. Firstly, an effective off-campus practice base or industrial cooperation enterprise must be established as a basis to ensure that industrial project projects enter the curriculum implementation environment through effective forms; secondly, the industrial subject guarantee mechanism needs to be reasonably constructed to ensure the timely connection and effective implementation of curriculums and industry research during the curriculums implementing and provide an important guarantee for the integration of innovative design of the project; Third, the rational allocation of teacher resources, the proportion of teachers in the school theoretical teaching, appropriate industrial practice teaching teachers, and timely use of dual tutor teaching mechanism are necessary to protect teacher resource basis of training the talent. Finally, it is necessary to ensure that appropriate proportions of courses use self-provided lecture notes or teaching materials in order to respond to changes in product innovation design requirements and industrial demand.

\section{The Modular Design of UED Course System}

UED modular course system includes public basic course modules, professional basic course modules, professional course modules, professional optional course modules, and practice session modules. The five modules' levels are gradually increased. The curriculum types configured by each module are closely following the changes in market demand. The curriculum system architecture has been constantly innovated, and the position of the curriculum system is based on the industry needs and the training of qualified and comprehensive modern design talents. First, the systematization of work ability is taken as the goal, and the dynamic construction of the UED curriculum system is initiated in the direction of breakthroughs in the actual needs of the user experience industry; secondly, the use of computer-assisted education in the form to develop curriculum-based course so as to find visual communication, The correlation and difference between the three directions of industrial design and interaction design make the curriculum dynamic collocation and complement of each other, so as to ensure the horizontal correspondence between the courses and the vertical progressive relationship. Third, the scientific research project and teaching practice should be closely related, and real projects should be introduced to comprehensively cultivate the students' abilities to use theoretical knowledge, the adaptability of the workplace, and the comprehensive application of skills.

\section{Integration of UED Curriculums System}

Based on the curriculum design of interactive design majors in famous universities both at home and abroad, the development of multidisciplinary blended curriculum content and the establishment of a comprehensive UED curriculum system are the primary tasks for the current dynamic construction of the UED curriculum system. For example, interface design, design psychology, and information visualization are all based on their own comprehensive independence. They incorporate the logic and comprehensiveness associated with other courses and disciplines, and thus exhibit diverse and dynamic features. The comprehensive curriculum system is an important foundation for comprehensively enhancing students' comprehensive ability and promoting students' formation of comprehensive and complete cognition. It can help students avoid falling into narrow, one-sided traps of thinking, and come up with new ideas through the integration of their own diverse knowledge. In fact, it is a creative process.

\section{CONCLUSION}

UED is a kind of discipline with high experiment ability and operability. UED related curriculums of Chinese design colleges are mainly lack of systemization curriculums and enterprises' engagement. Essentially, it owes to the shortage of education location and design concept guidance of courses What is of importance for UED developing is that it is necessary to make certain the role of UED in design, grasp 
related knowledge of each link in practical subject's UED progress and design systematic training plan of UED talents so as to systematically boost UED courses system.

\section{REFERENCES}

[1] Shin, Yoo Kyung. The Scenario-based Design Process for User Experience Design. Division of Digital Media The Graduate School of Ewha Womans University.2016.

[2] Jung Ha-Brookshire 2008 Exploring learning experience in textile and apparel management. International Journal of Fashion Design,Technology and Education 01/01/2008

[3] Wang Yaxi, Jin Yun, Li Junhua. Research on User Experience Design Education Centered on Design System[J]. Art Education, 2017(1).

[4] Xia Fan. The Brief Analysis of Application of UED Research Curriculum in Our Design Schools[D]. Wuhan University of Technology, 2011.

[5] Wang Sinuo. Content Comparison and Curriculum Innovation of Design Courses in Higher Art Colleges between China and Britain[D]. Harbin Normal University, 2011(6).

[6] Wang Wencong. The Brief Analysis of Information and Interaction Design Major's Current Situation and Curriculum Arrangement[J]. Education Practive, 2011(1).

[7] Jon Kolko. Translated by Fang Zhou. Thoughts on Interaction Design[M]. Beijing: China Machine Press, 2012-10-1.

[8] Giles Colborne, Translated by Li Songfeng. Simple and Usable Web, Mobile, and Interaction Design[M]. Beijing: Posts and Telecom Press, 2011-1-1.

[9] Zhang Jinsong. An Analysis of Interactive Design Teaching Reform for User Experience Industry[J]. Art \& Design, 2012(12).

[10] Liu Yi. Interaction Design Education Analysis under Studio System - Taking Guangmei Interaction Design Studio as Example[J]. Art \& Design, 2012(3).

[11] Yi Lingyun. University Core Curriculum System Research of Digital Media Major[D]. Wuhan: Central China Normal University, 2008-5.

[12] Tsinghua Thinker, Shi Yuanchun. Multidiscipline, Integration and Innovation [DB/OL],

[2016-12-20]. http://www.sohu.com/a/122101312_558434. 